\title{
Lecture three: From empathy to embodied faith: Interdisciplinary perspectives on the evolution of religion
}

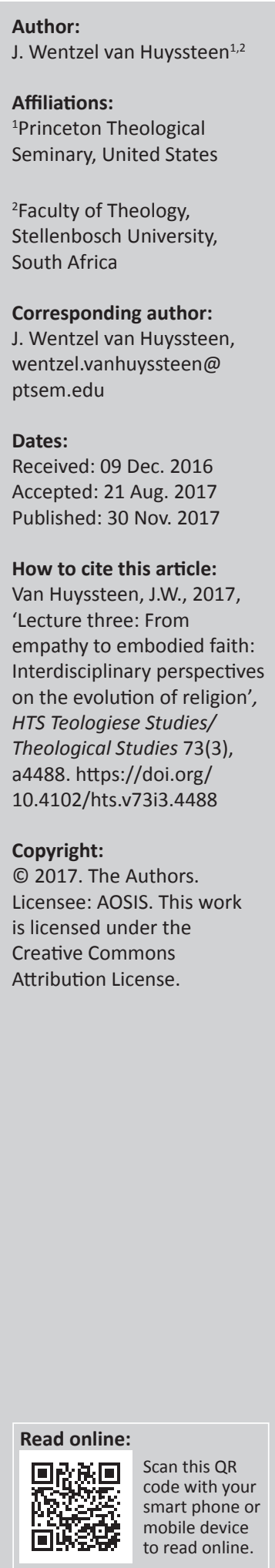

In a series of three articles, presented at the Goshen Annual Conference on Science and Religion in 2015, with the theme 'Interdisciplinary Theology and the Archeology of Personhood', J. Wentzel van Huyssteen considers the problem of human evolution - also referred to as 'the archaeology of personhood' - and its broader impact on theological anthropology. This trajectory of lectures tracks a select number of challenging contemporary proposals for the evolution of crucially important aspects of human personhood. These are aspects that were all of great significance for Darwin: the evolution of cognition, the evolution of imagination, music and language, the evolution of morality, and the evolution of the religious disposition.

\section{Introduction}

In my previous lecture we dealt with one of the most defining features of what it means to be 'human', namely the issue of morality and moral behaviour. As we saw, however, questions about morality and moral behaviour inextricably lead us to questions about the origins of morality and the emergence of human personhood. Here we saw that leading scholars like Christopher Boehm and Maxine Sheets-Johnstone unequivocally and convincingly answer the origin of morality question by pointing directly to the evolutionary emergence of the capacity for morality in natural history.

In a recent review of Boehm's book, Moral Origins, Dennis L. Krebs strikingly contrasts these evolutionary views with the popular traditional biblical, Christian view: on this view (so Krebs), God endowed humans with morality - or at least with innocence - when he created them. God then asked only one thing of the first humans God created, that they resist the temptation to eat fruit from the Tree of Knowledge. And, as we all know, Eve, and eventually Adam, succumb, which brings a quick end to the natural, God-like goodness of the human species. In this way Adam and Eve, and all their offspring, become afflicted with 'Original Sin', and as Krebs puts it, become 'bad by nature' - a 'harsh price for us to pay for a curious moment in one of our original ancestors' (cf. Krebs \& Denton 2013:9). According to Dennis Krebs, any evolutionary account of the origins of morality 'bites deeply into the fruit of the Tree of Knowledge' and shows that the new human species was not created in one fell swoop a few thousand years ago, but rather took form slowly over hundreds of thousands of years as humans branched off from other primate species (cf. Krebs \& Denton 2013:10). On this view is presupposed that the original early state of humans was primarily immoral and that a state of morality emerged gradually over tens of thousands of generations. The primary force at work in evolutionary accounts, the ultimate source of human morality, thus seems to be not God, but evolution (cf. Krebs \& Denton 2013:10).

Dennis Krebs has, of course, in this piece accurately portrayed the standard, if not classical, conflict between biblical and scientific views. However, in my previous two lectures I have attempted to show that there does not have to be such a final 'either/or' choice for Christian believers when it comes to evolution and evolutionary matters. Now, if God can be seen as the author of the evolutionary emergence of morality, can God also be seen as the 'hand' behind the evolution of our religious disposition? Put differently, does the natural history of morality teach us anything at all about the natural history of the very human religious sense (cf. Krebs \& Denton 2013:9-10)?

In my first lecture we saw that anthropologist Agustin Fuentes turns the current discussion on the evolution of religion on its head by arguing persuasively for a direct link between human evolution, the evolution of imagination and the imaginative as our permanent perceptual state, and in this way lays the groundwork for the emergence of metaphysical ideas, and, ultimately, the natural emergence 
of the religious sense. Fuentes' strongest argument, however, is that the reality of imagination, ritual and some form of metaphysical engagement with the world is inextricably entangled with our having become human beings. This dovetails closely with my own earlier argument that there is an evolutionary naturalness to the emergence of religious imagination (van Huyssteen 2006; 2011:143-160). With this similar move, Fuentes also avoids the epistemic trap of finding the origin of religion either in adaptations via natural selection or in seeing religious belief as only a by-product of our cognitive complexity. On the contrary, the origin of and capability to have religious beliefs do not lie wholly in the power or the content of religious beliefs as such, nor only in underlying neurological structures themselves, but rather is characterised by the interactive way in which humans all through prehistory have negotiated the world. Agustin Fuentes and I, in spite of our radically different disciplines, approaches and methodologies, completely agree that a necessary prelude to having religion is indeed the emergence of a human imagination and the embodiment of a quest for meaning as part and parcel of the distinctive human niche that has facilitated our flourishing as a species.

This is exactly why Fuentes could argue that evolutionary narratives alone will not get us a full explanation of why we are the way we are. This is also why the interaction between anthropology and theology can potentially provide a more robust narrative when we consider our human niche, our perceptual life-world. A better understanding of cooperation, empathy, compassion, the use of and engagement with materials, symbols and ritual, and the notion of a semiotic landscape in which humans and our immediate ancestors existed, do indeed move us along in our analysis of what it meant to become human. And the understanding of all of this is indeed a true interdisciplinary process. And it is this process that creates the possibility for an imaginative, potentially metaphysical and eventually religious experience of the world. This should lead to a better understanding of the ubiquitous importance of the propensity for religious imagination and the reality of religious experiences for Homo sapiens sapiens. Again, this does not imply an argument for any particular adaptive function of religiosity, but rather we have an argument that in an evolutionary context, neither religion nor religiosity could suddenly have appeared fully blown, and it is therefore valuable to search for the kinds of structures, behaviours and cognitive processes that might facilitate the eventual appearance of such patterns in human beings. If having an imagination is a central part of the human niche, and this imagination is a basal element in the development of metaphysics, one could indeed see how both adaptive and imaginative, creative perspectives could employ that fact as part of their understanding of the human.

For Christian theologians, this provides an exciting bottom-up view of the spectacularly complex way in which God has shaped and prepared our species to be physically, mentally and spiritually 'ready' for faith. I believe that my original intuition that there is a naturalness to human imagination, even to religious imagination, that facilitates engagement with the world in some ways that are truly distinct from other animals even closely related hominins - thus becomes even more plausible. As Fuentes argues, if this is indeed the case, it provides a small, and fruitful, addition to the toolkit of inquiry for both evolutionary scientists and interdisciplinary theologians interested in reconstructing the long, winding path to humanity.

\section{Religion and neural dispositions}

The 'natural history of the religious imagination' has become a prominent and challenging feature in contemporary interdisciplinary discussions. The recent work of neuroscientist Patrick McNamara has added an interesting and provocative dimension to the issue of the natural history of the religious imagination. For McNamara it is exactly the deep religious propensities of the human mind that cannot be explained by a reductionist evolutionary account of human nature and behaviour only. In his book, The Neuroscience of Religious Experience (2009), McNamara develops his own central conviction that religion is a defining mark of what it means to be human, as emblematic of its bearer as the web for the spider (cf. McNamara 2009:ix). The special focus of McNamara's work, however, is to examine the phenomenon of religion through the eyes of the human self. Strikingly, in spite of the self's great dignity and worth, it is still treated by religions as divided, conflicted and in need of salvation. Most importantly, McNamara argues that there is a considerable anatomical overlap between the brain sites implicated in religious experience and the brain sites implicated in the sense of 'self' and self-consciousness. This accounts for the crucial conclusion that religious practices often operate to support a transformation of self such that the self becomes more like an 'ideal self' whom the individual hopes to become (cf. McNamara 2009:xi). In this sense, religious practices directly contribute to the creation of a unified self-consciousness and to what McNamara calls an ideal 'executive self'. So, when religions are operating normally, they tend to create a healthy, unified and integrated sense of self. Religions accomplish this feat by promoting a cognitive process that McNamara calls decentering (2009:44f.), where religious practices help to build up a centralised executive self.

McNamara's bold claim, then, is that religion is irrevocably a central part of the evolution of symbolic and religious behaviour and of the construction of a centralised, 'executive' self. As for the evolutionary status of religion, this implies that religion is not an unfortunate by-product of more useful cognitive capacities of the human mind). On the contrary, this implies that religion is indeed an adaptation, which is confirmed by the fact that the practice of religious rituals and belief in supernatural agents occur in virtually all human cultures (cf. McNamara 2009:249). And it is precisely religion's impact on the problems associated with the self and consciousness that could be seen as adaptive. The self and its default position, the divided self, should thus be taken into account when discussing the evolutionary history of religion (cf. McNamara 2009:253).

Patrick McNamara's neuroscientific argument for the adaptive status of religion has recently found interesting and, up to a 
point, converging support in the work of well-known New York Times science writer, Nicholas Wade. In his book, The Faith Instinct: How Religion Evolved and Why it Endures (2009), Wade has made the point that religions normally point to the realm of the supernatural, thus assuring people that they are not alone in the world. Many - both believers and atheists - still find it difficult to understand religious behaviour from an evolutionary perspective: on the one hand, people of faith may not like the idea that the mind's receptivity to religion has been shaped by evolution; on the other hand, those who are hostile to religion often do not embrace the idea that religious behaviour evolved because it might have conferred essential benefits on ancient societies and their successors (cf. Wade 2009:5). Wade, however, argues explicitly that an 'instinct for religious behaviour' is indeed an evolved part of human nature. Because of the definite survival advantage conferred on people who practiced a religion, the behaviour - whether adaptive or non-adaptive - became written into our neural circuitry at least 50000 years ago, and probably much earlier (cf. Wade 2009:5, 6). Or, as Wade puts it, religion is a complex cultural behaviour built on top of a genetically shaped learning machinery (cf. Wade 2009:5). People are born with the innate ability to learn the language and religion of their communities, and in both cases, culture supplies the content of what is learned. This is also why languages and religions differ so widely from one society to the next, while remaining so similar in their basic form.

Against this background, Wade's definition of religion emerges: religion is a system of emotionally binding beliefs and practices in which a society implicitly negotiates through prayer and sacrifice with supernatural agents, securing from them commands that compel members, through fear of divine punishment, to subordinate their interests to the common good (cf. Wade 2009:15). As to the crucial and defining role of morality in religion, Wade thinks religion and morality share a common feature that reflects their origins as evolved behaviour: both are rooted in the emotions (cf. Wade 2009:17), and both religious knowledge and moral intuitions appear in the mind as strong convictions, not as neutral facts. Wade makes the interesting point, also argued - as we saw earlier - by Frans de Waal, that morality in a sense is older than religion, because we now know of its roots in primate behaviour. In this sense one could say that religious behaviour was engrafted on top of the moral sense in the human lineage alone (cf. Wade 2009:17). Understanding how moral intuitions evolved thus makes it easier to see that religious behaviour also has an evolutionary origin. Frans de Waal's work on building blocks of morality in primate behaviour, and its direct links to empathy and reciprocity (cf. De Waal 2006), already argue for this important fact, and clearly hominins and later humans would have inherited these building blocks from their apelike ancestors and developed them into moral convictions. Evolutionary biology thus gives us a fascinating new explanation for moral instincts and for religious intuitions: moral behaviour and the religious disposition do not originate from 'outside' the human mind or even only from conscious reasoning, sources often favoured by theologians and philosophers, but rather have been wired into the genetic circuitry of the mind by the process of evolution (cf. Wade 2009:19).

\section{Religion and empathy or attachment}

The important work on human personhood and the origins of morality, and specifically embodied empathy, by scholars as diverse as Maxine Sheets-Johnstone and Frans de Waal, finds a particularly exciting enhancement in the work of psychologist of religion, Lee A. Kirkpartick. Kirkpatrick broadens notions of empathy now to include attachment theory, and this now extends not only to the embeddedness of empathy in evolutionary history (as already became very clear in the work of Frans de Waal; cf. De Waal 2006) but also to direct implications for religious belief, and particularly for the evolution of religion. In his book, Lee A. Kirkpatrick (2005) addresses seminal questions such as, why has religion played such a strong role in all human cultures throughout history? Despite the remarkable diversity of forms of religious belief, why have certain common themes consistently emerged? Importantly, in this work Kirkpatrick consistently places psychology of religion in a larger evolutionary context, and within this framework, attachment theory provides a powerful lens through which to reconceptualise and advance the embodied aspects of religious belief and behaviour.

Rejecting the notion that humans universally possess religionspecific instincts or adaptations, Kirkpatrick argues that religion instead should be seen as a by-product of numerous psychological mechanisms and systems that evolved for other functions. Among these systems are empathy and attachment. Applying attachment theory to religion, Kirkpatrick identifies key parallels between early attachment relationships and adult romantic relationships, on the one hand, and an individual's perceived relationship with God, on the other hand. Seeing God as an attachment figure offers new ways of thinking about such core religious phenomena as images of God, prayer, religious development and conversion. On this view, evolutionary perspectives are now greatly influencing the ever-increasing popularity of attachment theory. In fact, for Kirkpatrick the emerging evolutionary perspective attempts something really new: the tying together of attachment, empathy, love, caregiving, and mating into a larger, coherent framework (cf. Kirkpatrick 2005:51), a framework that now includes a very distinct religious dimension. In fact, Kirkpatrick wants to argue how attachment processes are involved in many aspects of religious belief and also directly in the evolution of religion itself.

Furthermore, and important for any discussion of the evolution of religious belief, this approach serves as a reminder that the attachment system, and empathy, is only one of numerous evolved systems for regulating cognition, emotion and behaviour in functionally distinct classes of relationships (cf. Kirkpatrick 2005:74). This will invariably lead to the question of how the attachment system maps onto other neurological patterns, for instance, ecstatic experiences, and 'hypersensitive agency detection device' (HADD), in the brain. Kirkpatrick, therefore, is thus suggesting that the cognitive-emotional machinery of the attachment system provides a kind of deep 
structure or universal grammar for thinking about gods or other deities. This cognitive machinery is then employed readily for manipulating these ideas and drawing further inferences from them. Because the attachment system is species-universal, the influence of this same deep structure is evident in the beliefs about gods in many cultures. At the same time, however, the parameters of the attachment system are set differently in different people by virtue of actual experience, giving rise to individual differences in some of the details of religious belief (cf. Kirkpatrick 2005:126). There is also increasing evidence that attachment, with a clear adaptive function in infancy and childhood, functions differently, for evolutionary reasons, in adulthood. In adulthood, attachment is 'the tie that binds' certain relationships, especially romantic relationships and deep friendships together (cf. Kirkpatrick 2005:201f.). In this sense, the attachment system - already in place for infancy and childhood - was adopted by natural selection as a suite of evolved mechanisms already well designed for the purpose of producing powerful emotional bonds, motivating commitment to a relationship, maintaining proximity between two individuals and natural selection then reassigned the system the new function in adulthood. Kirkpatrick sees this process of exaptation), in which an adaptation for one function is later coopted and further evolved for use in solving a different adaptive problem, as indeed a common evolutionary process (cf. Kirkpatrick 2005:201).

When Kirkpatrick finally turns to the evolution of religion, he can now make explicit a general perspective that has been implicit throughout his work: religion is not itself an adaptation; humans do not possess, as part of our speciesuniversal evolved psychological architecture, mechanisms designed by natural selection specific for the purpose of generating religious belief or behaviour as a solution to any particular adaptive problem (cf. Kirkpatrick 2005:238). The attachment theory and its embodied empathetic disposition as outlined here should be seen as simply one part of a much broader model in which the attachment system represents just one of many domain-specific psychological mechanisms that have been co-opted in the service of religion and religious belief. Religion activates attachment processes but also many other psychological processes as well, and it is probably this combination that is responsible for its widespread success and staying power (cf. Kirkpatrick 2005:239). The path from genes to religious belief is, therefore, clearly a very long and circuitous one (cf. Kirkpatrick 2005:327).

What is interesting for an interdisciplinary theologian like myself (cf. van Huyssteen et al.) is that Kirkpatrick leaves open the possibility for positively interpreting the value and integrity of religious belief as he warns against the so-called veridicality trap: the common but patently false assumption that if certain beliefs can be understood and explained scientifically, then the beliefs themselves are by implication false. On the contrary, there is no reason why any scientific approach to understanding religion need assume that the beliefs under study are either ontologically true or false. To believe that the origins, neuropsychological or otherwise, of a belief necessary imply that it is not true (because it has been 'explained') is a classic example of the genetic fallacy (cf. Kirkpatrick 2005:353).

In fact, the human brain or mind was designed according to the sole criterion of inclusive fitness and is thus designed to be adaptive. It is decidedly not designed to be 'accurate' or 'correct' as judged by logical or other empirical standards. Often this leads to correct intuitions and inferences, and being 'correct' is indeed often adaptive. Once this is acknowledged, there is no a priori reason to believe that any particular kind of belief, whether religious or not, should be expected to be correct or incorrect. The mind is designed in such a way that, depending on any number of factors, it sometimes draws correct inferences and sometimes incorrect ones. In this sense, an evolutionary psychology of religion should address the question of why and how people come to hold (or, come to reject) particular beliefs in which we are interested, irrespective of the question of whether they are true or false (cf. Kirkpatrick 2005:354).

\section{The cognitive science of religion and faith}

Without any doubt, the cognitive science of religion (CSR) is the dominating voice in current discussions about the origins and evolution of religion. CSR is an interdisciplinary research program that includes the fields of the cognitive sciences (cognitive linguistics, cognitive psychology, cognitive neuroscience, artificial intelligence studies and cognitive anthropology) and the study of religion. An excellent guide through the vast amount of literature generated by a virtual explosion of literature in this field is given in Aku Visala's (2011) Naturalism, Theism and the Cognitive Study of Religion. Religion Explained?. Visala argues correctly that central to this research program over the last 20 years has been the application of theories from both the cognitive sciences and evolutionary epistemology in order to explain the general forms of religious ideas and behaviour (cf. Visala 2011:13-15). Within the larger and loosely integrated fields of cognitive science and evolutionary psychology, there has emerged a relatively tight-knit group of scholars engaged in what now is known as 'cognitive science of religion' (cf. Visala 2011:4ff.). In this particular book, Visala discusses and critically analyses the work of four prominent members of this group, namely Pascal Boyer, Scott Atran, Justin Barrett and Dan Sperber.

One of the founding fathers of cognitive science is Noam Chomsky who claimed that language acquisition and structures of human languages are strongly constrained by innate, psychological capacities of language processing. In this sense, according to Visala, Chomsky was the first to formulate the basic idea of 'innateness' or 'nativism' (cf. Visala 2011:11). Here the human mind is not a 'blank slate' that just passively records and memorises information presented to it. On the contrary, the human mind comes with intuitive, innate biases, schemas, models and mechanisms that actively shape the acquisition and transmission of information.

The second major development in CSR was the emerging consensus from cognitive psychology according to which 
the innate biases and information processing tendencies of the human mind have different effects in different domains of knowledge. The basic idea of this 'domainspecificity hypothesis' is that, already in the very early stages of human development, we can already see very specialised and context-sensitive cognitive mechanisms at work. (cf. Visala 2011:6).

The third essential development contributing to the birth of CSR was the emergence of cognitive anthropology in reaction to developments in cognitive psychology. In this development, the human mind does not just acquire and memorise all information that is available and presented to it in a given cultural environment. On the contrary, the relationship between culture and mind is a two-way process: the mind not only acquires cultural information but also shapes and transforms it. In light of this, the anthropologist can now assume that underlying all cultural forms and diverse belief systems is a similar cognitive architecture shared by all humans (cf. Visala 2011:6).

The fourth development that contributed to the emergence of CSR was the emergence of cultural Darwinism, that is, theories that could now use conceptual resources from Darwinian evolution to actually model cultural evolution. CSR combines all four of these developments in explaining cross-culturally recurrent patterns in religious belief and behaviour. This also implies that religious ideas and practices are informed by our non-religious cognitive systems working in different domains. In this view, there is no single type of 'religious cognition' or 'religious module' in the human mind, but the same general causes that explain other non-religious features of human cognition also explain religious cognition.

Some of the most important conclusions gleaned from these developments have consistently implied that the study of religion is explanatory rather than interpretative in nature. For many, this has signalled a worrisome shared antipathy towards hermeneutical and sociological approaches, and particularly the work of Pascal Boyer (2001) who has often been criticised for this (cf. Visala 2011:17f.). The idea that the study of religion should aim to explain rather than understand religion, is already, I believe, highly problematical from a philosophical point of view and also from a philosophy of science point of view. Importantly, though, Boyer does claim that the phenomenon of religion is not to be considered sui generis, as an exclusive category all on its own (cf. van Huyssteen 2014:134f.). In this sense, religion is considered by CSR as a part of human culture and human nature and thus as a natural phenomenon (cf. Visala 2011:17f.), which, I believe, is in direct continuity with the claims and arguments of traditional evolutionary epistemology (cf. van Huyssteen 2006:75-110). Of crucial importance here is that religious beliefs and behaviours are seen as by-products of the modular cognitive system that had an adaptive function in our ancestral environment. Rather than being an adaptation, religion on this view is a by-product of systems selected for other functions (cf. Visala 2011:41). This will imply, as is well- known in current discussions, that the choice between whether religion is adaptive or non-adaptive, is already much more polarised than in the case of Kirkpatrick's carefully nuanced descriptions of the evolutionary status of religions.

Indeed, the primary debate among scholars who study the evolution of religion concerns whether religion is an adaptation of a by-product. (cf. Sosis 2009:315ff.). The dominant position in the field for some time now has been the view that religious beliefs and religious behaviours are by-products of cognitive processes and behaviours that actually evolved for other purposes. A smaller group of scholars maintain that religion is an adaptation for extending human cooperation and coordination. In addition, Aku Visala (2011:113) has also lifted up the important problem of the scope of CSR and quite specifically asked the important question about the scope, the boundaries and limitations of CSR explanations of religion. At the same time, however, it has become clear how important the distinction between adaptationist and non-adaptationist accounts of the origin of religion has become. In his discussion of these controversial issues, biologist Jeffrey Schloss has concluded correctly that, while the proposal for the non-adaptationist status of religion has received much attention, the idea of a HADD, has arguably received the most attention in discussions within and outside the field (cf. Schloss \& Murray 2009:17). Schloss' most important criticism against CSR, however, can be stated as follows: the real Darwinian question of what selective regime accounts for these dispositions is largely separate from and considerably less addressed than the empirical demonstrations of their existence and operation (cf. Schloss \& Murray 2009:17f.).

Jeffrey Schloss and Michael Murray's recent work on CSR is proving to be not only especially valuable for the ongoing interdisciplinary discussion of the scope of CSR claims but especially insightful for theologians who are interested in the evolutionary status of religion. Murray (2009), in an essay on the scientific explanations of religion and the justification of religious belief, puts it forcefully: the different models that are now used to explain religion show not one thing more than that we have certain mental tools (perhaps selected, perhaps 'spandrels') which under certain conditions give rise to the belief in the existence of entities which tend to rally religious commitments. Pointing that out, however, does nothing, all by itself, to tell us about whether those religious beliefs are justified or not. The mere fact that we have beliefs that spring from mental tools selected for by natural selection is, all by itself, totally irrelevant to the justification of beliefs that spring from them (cf. Murray 2009:169).

Even more important is Murray's following question: what is it about religious beliefs, formed by the working of various psychological mechanisms and honed by natural selection, that makes us think that religious beliefs are epistemically suspect? Why would brain or genetic mechanisms spun from natural selection be downright unreliable only in the case of religion? (cf. Murray 2009:177f.; moi in Alone!). In another essay, Michael Murray and Andrew Goldberg have argued that the main problem with non-adaptationist theories is that 
they seem to render the view incapable of explaining what they set out to explain: the pervasiveness of religion across times and cultures. If the emergence and evolution of religion require such a highly contingent confluence of cognitive circumstances, we may indeed have an explanation why religion sometimes emerges here and there (cf. Murray \& Goldberg 2009:179ff.). Against this background, I believe, it becomes quite clear, as also Kirkpatrick, McNamara and Lewis-Williams, each in their own way, has pointed out, that not just HADD but also empathy, attachment, altered states of consciousness, etc., all add to the bigger picture of the plausibility of religious beliefs and also to the compatibility of religious beliefs with human nature.

\section{Embodiment and the evolution of religion}

In theologian Wesley J. Wildman's (2009) important book, Science and Religious Anthropology, various strands from our conversation so far now flow together in an exciting and challenging way. The central argument of this work, not surprisingly, supports a naturalistic interpretation of the human being, but quite specifically the human being as Homo religiosus. Religion in this specific sense suffuses every aspect of human life, and Wildman makes it clear that our value of commitments, our efforts at meaning construction and our socially borne explorations of life possibilities all reach far beyond the historically most prominent forms of religiosity. Wildman, in language reminiscent of Patrick McNamara, puts it well: at an axiological level, beneath the most overt beliefs and practices of both religious and non-religious people, we find Homo religiosus. From there on we can trace the impact of human religiosity in a more general sense on existential levels, on moral awareness and on the social construction of reality (cf. Wildman 2009:xvii). Wildman thus wants to present a religious anthropology by focusing on the embodied Homo religious and by enlarging the scope of religious behaviours, beliefs and experiences, to encompass everything relevant to human meaning and value.

In the end, Wildman develops his own, and in my view the most plausible view, that religion in evolutionary terms is a combination of side-effects of both adapted and non-adapted features of the human organism (cf. Wildman 2009:37f.). And, whatever one's views of theological truth claims, the evolutionary story of the origins of religion is directly relevant to assessing the meaning and value of religion, as well as religious claims about human beings (cf. Wildman 2009:42). In light of this, Wildman now also asks the burning question: is religion an evolutionary adaptation, increasing fitness in and of itself and originating because of the adaptive functions of religious behaviours, beliefs and experiences? Or, is religion a sideeffect of a collection of adapted traits? Or is it possible that religion has no genetic component at all and finds its origin only in a long history of cultural expressions?

There is indeed overwhelmingly strong evidence against the extreme view that no aspect of religion is genetically related or evolutionarily conditioned. Similarly, for Wildman it is clear that the evidence for religion as an adaptation so narrows the focus to one or two adapted 'religion traits' that only a fraction of the varied phenomena of religion are registered in the explanation. He argues, therefore, in language reminiscent of that of Lee Kirkpatrick (cf. Kirkpatrick 2005), that it seems highly likely that the evolutionary explanation for the origin of the multifaceted reality of religious behaviours, beliefs and experiences, must lie somewhere between these extremes. Religion, in other words, is evolutionarily conditioned, possibly in a few special respects by virtue of the adaptiveness of specifically religious traits, but in most respects by virtue of side-effects of traits adapted for some other, primarily and originally nonreligious purpose (cf. Wildman 2009:48).

In the end, Wildman does state that little is gained for the religionist or theologian by mastering the intricate debate over adaptations versus exaptations versus spandrels because little depends in the details of how religion evolved once it is granted that religion is in fact partly the product of evolutionarily processes. The general fact that the religious sense and religion is partly the product of evolutionary processes indeed proves to be the most salient point for any religious anthropology (cf. Wildman 2009:54, 55). And at this point Wildman directly refers to Lee Kirkpatrick (2004), who has argued that religion is indeed a complex combination of side effects that have a variety of adaptive functions. And Wildman (2009) states:

Understanding religion in evolutionary terms predominantly as a combination of side-effects of both adapted and non-adapted features of the human organism, possibly with a few directly adapted features, is the hypothesis that I regard as possessing the most prima facie plausibility. (cf. p. 56)

Crucially important from the perspective of this paper is Wildman's consistent and enduring focus on our embodied religious propensities. Because the human brain furnishes the cognitive, emotional and motor capacities underlying our extraordinary range of religious behaviours, beliefs and experiences, it is reasonable to expect the neurosciences to have at least as much transformative importance for religious anthropology as the evolutionary sciences (cf. Wildman 2009:87). And important for the current discussion in the CSR is Wildman's argument that biases exist in the human cognitive system either because they have been selected in the evolutionary process for their survival benefits or because they are side-effects of other traits selected for their usefulness (cf. Wildman 2009:94). This enables Wildman also to focus on three domains in which a sharp awareness of human bodies and their functions is vital for understanding the human being as Homo religiosus: sociality, morality and, finally, religious and spiritual experiences. In all three of these areas it is bodies that make religion, in the broadest sense of the word, not only possible, but also inevitable. Bodies shape the cognitive and emotional form that religion takes in individuals, and the social and moral practices that religions manifest in groups. Our bodies do not completely determine who we are, but they do constrain without determining, and as such but they directly shape what we are and do, how we 
think and interpret, how we love and how we construct our religions (cf. Wildman 2009:118). Thus, our religious and spiritual experiences arise from a suite of bodily capacities with neurological and sensory roots that have vast existential and social impacts (cf. Wildman 2009:141).

Some scholars, of course, have argued that religion is an evolutionary phenomenon in a double sense, that is, both on a biological and social or cultural level. Scholars like James McClenon (1997; 2002) and David Lewis-Williams (2002), for instance, have claimed from very different disciplinary backgrounds that altered states of consciousness, ecstatic religious experiences and forms of shamanism are not only neurophysiologically grounded but also represent the earliest forms of prehistoric religion. McClenon and Lewis-Williams have also provided possible scenarios for how shamanic rituals could have evolved by natural selection in the human ancestral environment, perhaps as early as 30000 years ago. Lewis-Williams has also argued persuasively that beliefs in a supernatural realm persist worldwide. In addition, it is exactly the persistence of religion into our modern, materialistic Western milieu that in fact points to the answer to the problem of the origin of religion: instead of religion being an answer to social and psychological needs, and in place of the supposed evolutionary stages of religion, he prefers to think of origin-asprocess (cf. Lewis-Williams 2010:137). I believe this plausible idea can be elaborated as follows: when reflecting on the evolutionary origins of religion, on the one hand, and the ongoing process of the evolution of religion, on the other hand, these two dimensions of the evolution of religion cannot be separated: the reasons why religion persists today are, in some fundamental ways, the same as those that explain why religion came into being in the first place.

\section{Cognitive science of religion and faith?}

Teehan is correct in stating that the application of the methods and findings of cognitive science to religious beliefs and practices constitutes one of the most promising approaches to understanding the religious mind and certainly establishes a new front on the religion-science debates (Teehan 2014:169). It is already making significant claims about the nature of religion: it has been touted by some as the final nail in the coffin of religious belief and as decisive evidence for the incompatibility of science and faith; while others, including some major figures in the field, argue that there is no conflict at all. Teehan argues, in this paper, that both sides actually overstate their position: cognitive science does not entail atheism, nor is it a conclusive case against a religious world view that some fear or hope that it is (cf. 2014:269). However, cognitive science, for Teehan, grounded in an evolutionary perspective, 'shakes the foundations' of religious belief in a more profound way than evolutionary theory has done so far.

Basically, cognitive scientists argue that belief in gods (or God) arises because of the natural functioning of completely normal mental tools working in natural contexts. Just what these mental tools or cognitive dispositions are, are continually being debated, but there is a growing consensus on the importance of the following four 'tools':

1. Hypersensitive Agency Detection Device: Humans have a well-known predisposition to interpret the world in terms of agency. As we saw, we are hypersensitive to the presence of agents, detecting agency even when there are no intentional agents present. It is then argued that the universal tendency to believe in God, ghosts, spirits, etc., is grounded in this evolved predisposition (cf. Teehan 2014:168; also for other cognitive scientists like Boyer, Atran, and Barrett arguing this).

2. Theory of Mind: Not only do we perceive the actions of agents but we also ascribe mental states to those agents (see references). In this way we perceive agents as acting with intention, having desires, emptions, plans, goals, etc. (see also my comments on ToM in Lecture 1).

3. Common-sense Dualism: Research suggests that humans have different cognitive systems for dealing with physical bodies and mental events (cf. Teehan 2014:168). As a consequence of this, it is an intuitive move to conceive of bodies without minds and minds without bodies. As Paul Bloom (2007:149) puts it, we think of goodies and souls as distinct.

4. Promiscuous Teleology: This phrase originated with developmental psychologist Deborah Kelemen (2004) whose research indicates that we also naturally interpret the worlds in teleological terms, that is, we intuitively ascribe purpose and design.

Evolved mental tools such as these predispose the mind to interpret the world in terms that give rise to religious beliefs and practices. Cognitive science, therefore, clearly has important implications for both theists and atheists: in terms of the critics of religions, the findings of CSR change the nature of such criticism. Religious belief can now not just be seen as the result of ignorance or of irrational or superstitious thinking, or as an opiate of the masses or a defence mechanism against death (Teehan 2014:169). In fact, religion from the perspective of cognitive science is rather the outgrowth of natural cognitive tools functioning to help us make sense of our world. In other words, the cognitive tools that give rise to and sustain religious belief and practice are in fact part of human nature. Or as I, and others like Wesley Wildman, Robert McNamara and Nicholas Wade and a host of others have argued, humans are naturally religious - Homo religiosis. And as we already saw earlier, to conclude that religion is a natural part of the human condition is not to suggest, of course, that any specific religious claims are true or that a religious interpretation of reality is accurate.

This, in fact, is what a cognitive scientist of religion like Justin Barrett would suggest: even if our natural tendency towards belief in God can be conclusively demonstrated to the work of evolved capacities, the Christian can still say that God used the process of natural selections to guide cognitive evolution to results in minds capable of coming to know God (cf.; Teehan 2014:171). What cognitive scientists who are 
believers, like Barrett, are suggesting is therefore not that evolutionary psychology or cognitive science provides arguments for belief in God: their conclusion is simply, but significantly, that evolutionary accounts of religions do not as such conflict with belief in God, in general, or with Christian belief, in particular (cf. Teehan 2014:171).

What is especially interesting in the new CSR debate is that a rather important shift in the 'evolution and faith' discussion seems to have developed in CSR during the past decade or two: instead of trying to show that evolution is true and then assert that Christianity must therefore be false, the new scientific study of religion attempts to use evolution to show that religions generally are mere by-products or 'accidents' of natural selection. On this view, evolution has endowed humans with particular mental facilities and social arrangements that prop up religious illusions. The basic thesis then is that, if evolution can in fact explain religious belief, then it can also explain it away, and then we have no need to appeal to the reality of God to account for those beliefs (Barrett 2009:76).

Most interesting for the interdisciplinary discussion with theology, however, is that someone from within CSR ranks is actually trying to show that religious faith (in this case the Christian faith) is compatible with the findings of CSR. In an argument that should be important to theologians, Justin Barrett, rather than seeing cognitive and evolutionary explanations of religion as hostile to Christianity sees much promise in the cognitive sciences to enrich our understanding of religion and religious belief. In his most recent work, Barrett gives an account of why belief in superhuman agents (gods) is historically and cross-culturally natural and universal by appealing to the naturally occurring properties of human minds. For Barrett, CSR indeed need not be an enemy of Christianity, but could actually prove to be compatible with (orthodox) Christian theology (Barrett 2009:77).

In one of his most recent contributions in Cognitive Science, Religion, and Theology: From Minds to Divine Minds (Templeton Science and Religion Series, eds. J. Wentzel Van Huyssteen \& Khalil Chamcham 2012), Justin Barrett sets out to show that (1) findings from cognitive science can potentially support or challenge theological claims; (2) theological positions can inform how and why one does cognitive science and what we should do with what we find; (3) the outcomes of religions can be studied through cognitive science and (4) cognitive science can uncover causes for features of religion, including why people have certain theological commitments (cf. Barrett 2012:viiiff.). For Barrett, as a Christian, how the human mind handles religious information may actually provide insights into the nature of revelation, or rather - I would say - how people perceive of revelation, how people understand scripture and how they interpret the natural world for messages from God.

In a move that, on my view at least, clearly harkens back to central themes from evolutionary epistemology, Barrett also argues that people all over the world entertain 'natural' religious beliefs: this kind of content-specific cognition is critical for making sense of the world around us.
Consequently, people the world over entertain religious beliefs and act upon these beliefs to form religions (cf. Barrett 2012:130ff.). It is in this sense that I would say that not just natural cognition but also embodied natural cognition informs religious experiences and practices. And it is our natural embodied cognitive tendencies that help to generate and support religious thought and then become elaborated in different ways - sometimes in ways that radically depart from the natural cognitive anchors and thus philosophically, I would say, result in theologies (cf. from HADD to conceptions of the Trinity).

For Barrett, this means that natural cognition thus creates receptivity to what he calls natural religion (cf. Barrett 2012:131ff.), a notion that he ties explicitly to John Calvin's notion of the semen religionis. In this sense, 'natural religion' is the cultural expression of numerous natural tendencies and dispositions that encourage belief in $\operatorname{God}(\mathrm{s})$. Against this background, I believe, one could indeed argue that theological ideas help to interpret experiences of agency detection for which humans themselves are not the apparent cause (cf. HADD experiences, altered states of consciousness, attachment experiences, etc.). In these ways, theological conceptions help to interpret and explain the perceived order and purpose of the world around us, help us to interpret adequately good fortune of misfortune, influence our moral evaluations and judgements and especially can help to make sense of human death and our yearning for life after death (cf. Barrett 2012:144ff.). For this reason, Barrett can argue that for the theologian to ignore cognitive science would be to surrender a useful tool for his or her scholarly of pastoral vocation (cf. Barrett 2012:146ff.).

From this perspective, one can now indeed say, contra explicitly atheistic scholars like Pascal Boyer, that a scientific explanation of how human cognitive systems form beliefs in God(s), only 'explains away' God if one already believes that God does not exit (cf. Barrett 2012:150). For believers, however, such explanations just specify the means by which God is naturally perceived and understood or misunderstood: a theology that teaches that people have no natural ideas about the divine but are fully dependent upon a 'special revelation' would indeed seem to be easily threatened by findings from the CSR (cf. Barrett 2012:151). On the other hand, I believe, theologies that recognise that humans naturally share a set of embodied moral intuitions and some general sense of the divine (or sensus divinitatis), would indeed gain a qualified support from cognitive science. In this sense, a theological understanding of humans, or theological anthropology, needs to publicly engage with facts revealed by the human and natural sciences, including cognitive science.

Most importantly, cognitive science provides evidence that humans have natural, embodied propensities towards believing in some kind of God. And it is this rudimentary sense of the divine, called a sensus divinitatis in traditional Calvinist theology, that not only appears to be natural to humans but also to develop very early (cf. Barrett 2012:161). 
In Calvin, the sensus divinitatis or semen religionis is 'divinely implanted in all men (sic)', refers to a numinous awareness of God and is as such closely connected to conscience:

these are the two principal parts of the light which still remains in corrupt nature: first, the seed of religion is planted in all men [sic]: next, the distinction between good and evil is engraved on their consciences. (cf. Calvin, I.iii.1)

This is followed by an even stronger statement from Calvin:

Therefore, since from the beginning of the world there has been no region, no city, in short, no household that could do without religion, there lies in this a tacit confession of a sense of deity inscribed in the hearts of all. (I.iii.1)

What we find here in Calvin, then, is the deep conviction that some sense of God 'is naturally inborn in all, and is fixed deep within, as it were, in the very marrow' (I.iii.1). In the light of contemporary discussions on the evolution of religion, it certainly does not get more embodied than this! And it is indeed this religious disposition, along with our natural moral sense, that has great potential to be substantiated and amplified by both the CSR and evolutionary biology.

A fascinating fact, of course, is that one recurrent and distinctive mark of religions is that gods frequently become connected with moral concerns (cf. Barrett 2009:88). Why is that? The answer for Barrett is found in the fact that naïve biology and naïve physics constantly assist us in our chronic need to make meaning and as mental tools guide us to search the environment for causal explanation and meaning. When these explanations fail because of unfortunate or bad events like sickness and death, HADD, Theory of Mind and other mental tools engage our intuitive desire for explanation. Most importantly, when agency is invoked, another mental tool kicks in, namely Intuitive Morality. Intuitive Morality generates non-reflective beliefs about what constitutes moral behaviour. In fact, from an early age, children appear intuitively to differentiate between moral codes and social conventions, and humans converge upon general rules of behaviour that typically frown on things like murder, adultery, theft, deception, treachery and cowardice, especially as directed against one's own group (cf. Barrett 2009:89). Clearly, our god concepts will gain in reflective plausibility by working in concert with these non-reflective beliefs. This leads Barrett to three important conclusions:

1. The naturalness of religious beliefs thesis is complete enough to begin exploring its implications for religious belief and its relationship with theological commitments.

2. As far as claims of the so-called new atheists are concerned: Barrett joins Schloss, Murray and Goldberg, by stating that explaining how beliefs come about - no matter how complete the explanation - says nothing about whether a belief is true or justified (Barrett 2009:96). Belief in other minds and belief in gods are both highly intuitive consequences of cognitive architecture operating on ordinary inputs. Both are non-empirical, widespread beliefs. Neither is directly weakened by increasing scientific knowledge about how these beliefs come about any more than knowledge of the visual system makes us suspicious that the visual world is not really there (Barrett 2009:96).

3. It is in this sense that the CSR is not an automatic antireligious tool or movement. In fact, one can consistently hold such an account of the evolutionary status of beliefs along with Christian theology. This does mean that thinkers with theological commitments have serious work to do (Barrett 2009:97), but a Christian version of the CSR remains possible (Barrett 2009:98f.).

\section{Conclusion}

In this lecture, I have argued that the question of the evolution of religion and of religious behaviour can never be disentangled from the broader issue of the evolution of the embodied human self. This implies that the evolution of distinctive traits and aspects of personhood like morality, sexuality, empathy and the religious disposition played a defining role in the evolution of human communication and interpersonal attachment and, along with the evolution of complex symbolic behaviour, combine to give us important insights into the evolution of religion and religious behaviour.

I believe good arguments have been made by various scholars for the fact that religion is not in itself adaptive. We humans do not possess, as part of our evolved neurological and psychological architecture, intuitive mechanisms designed by natural selection specifically for the purpose of generating religious beliefs or behaviour as a solution to particular adaptive problems. Empathy, Theory of Mind, attachment, altered states of consciousness, HADD and the evolution of the moral sense-intuitive morality should all be seen as one part of a much broader model in which the attachment system represents just one of many domainspecific mechanisms that have been co-opted in the service of religion and religious belief. Religion thus activates not only attachment processes but also many other processes like altered states of consciousness and HADD, and it is most probably this combination that is responsible for the widespread success and staying power of religious belief.

Religion, in other words, is evolutionarily conditioned, possibly in a few special respects by virtue of the adaptiveness of specifically religious traits, but in most respects by virtue of side-effects of traits adapted for some other, primarily and originally non-religious purpose. Understanding religion in evolutionary terms predominantly as a combination of sideeffects of both adapted and non-adapted features of the embodied human might be the most plausible hypothesis for beginning to understand the evolution of religion and religious behaviour. Thus, religious and spiritual experiences arise from a suite of bodily capacities with neurological and sensory roots and vast existential and social impacts (cf. Wildman 2009:56, 141).

Reflecting on the scope and limitations of the CSR approach is indeed important. Another critical question might be whether CSR deals only with the most general features of religious 
thinking and behaviour and actually excludes everything else that embodied humans think and do and that all distinctive features of religious traditions, as well as what religious people themselves identify as 'religious', actually seems to fall outside of the CSR's scope (cf. Laidlaw 2007:213ff.; Visala 2011:85f.). Most interesting for me, via evolutionary epistemology (cf. Van Huyssteen 2006:45-109), is that finally Justin Barrett presents a certain type of defence of theistic belief by grounding them precisely in the reliability of our cognitive systems (cf. Visala 2011:185f.). As theologians, both Niels Gregersen (2003) and I have argued, the naturalness of religious ideas actually supports religious claims rather than undermines them: if religious beliefs are largely produced by normal human cognitive systems and if we generally trust these systems, then we should not suspect them only in the case of religious beliefs (cf. Van Huyssteen 2006:53-109; Visala 2011:184).

As I have hinted at in this lecture, the evolution of morality is deeply intertwined with the evolution of the religious disposition, as well as with other distinctive traits of what makes us human. For religious believers, this certainly means that, if one accepts that evolution has profoundly shaped the human body, why not accept that it has profoundly shaped our embodied minds too? What evolution has done is to endow us with a predisposition for ultimate questions, to search for meaning and to learn and live the religion of a community, just as we are genetically predisposed to learn the language of our communities and construct moral codes on the basis of our genetically predisposed moral sense. All of this goes far beyond CSR's narrow theoretical focus on HADD alone. And in the light of our earlier discussion on the constructive role of niche construction in a broader and richer notion of human evolution, with religion, as with language and morality, it is ultimately culture, not genetics alone, which supplies the constructive content of what is learned, appropriated and believed. Finally, the overwhelmingly important questions of the evolution and of the moral sense and the religious sense leave theology and all Christian believers with a series of crucially important challenges.

- As I have tried to show in Lecture Two through a brief natural history of morality, evolution clearly and convincingly points to the fact that our moral propensities have emerged from a natural process. Recently Kenneth Reynhout (2015) has claimed that this could bring real focus to an all-important challenge for theology, namely that we must face the fact that some part of our 'sinful natures' are indeed 'natural' and not at all part of some 'postlapsarian state' after the so-called Biblical fall or corruption as narrated in the Bible. But of course, as we also saw in Chapter Two, the same natural process has also graced us for what is morally good, so clearly evolution has conditioned us for both antisocial and prosocial tendencies Reynhout puts this rather starkly: if what we call 'human sin' is the direct result of a natural process, then what are we really held accountable for? Why the need for salvation, for atonement, and the
Cross, and what does it mean to think of the gospel as good news for the human species?

- As far as the evolution of the religion sense (sensus divinitatus?!) is concerned, it is correct to say that an evolutionary challenge as presented specifically by the CSR does indeed not entail atheism; it is, however, not correct to say that cognitive science does not challenge faith in God. We must be able to argue why the personal belief that is implied in a personal faith commitment is justifiably compatible with the mental tools given to us by evolution and not rendered epistemically suspect by the fact that evolutionary theory provides us with a plausible account of where religious beliefs come from.

\section{Acknowledgements Competing interests}

The author declares that he has no financial or personal relationships which may have inappropriately influenced him in writing this article.

\section{References}

Barrett, J., 2009, 'Cognitive science, religion, and theology', in J. Schloss \& M. Murray (eds.), The believing primate: Scientific, philosophical, and theological reflections on the origin of religion, pp. 76-99, OUP, Oxford.

Bloom, P., 2007, 'Religion is natural', Developmental Science 10(3), 147-151.

Boyer, P., 2001, Religion explained: The evolutionary origins of religious thought, Basic Books, New York, NY.

De Waal, F., 2006, Primates and philosophers: How morality evolved, Princeton University Press, Princeton, NJ.

Gregersen, N., 2003, 'The naturalness of religious imagination and the idea of revelation', Ars Disputanti: The Online Journal for Philosophy of Religion 3, viewed 25 January 2017, from www.arsdisputandi.org

Kelemen, D., 2014, 'Are children "intuitive theists"? Reasoning about purpose and design in nature', Psychological Science 15(1), 295-301.

Kirkpatrick, L.A., 2005, Attachment, evolution, and the psychology of religion, The Guilford Press, New York.

Krebs, D. L. \& Denton, K.K., 2013, 'How did morality originate?', Evolutionary Psychology 11(1), 9-17

Laidlaw, J., 2007, 'A well-disposed anthropologist's problem with the "Cognitive Science of Religion"', in H. Whitehouse \& J. Laidlaw (eds.), Religion, anthropology and cognitive science, pp. 211-246, North Carolina Academic Press, Durham, NC.

Lewis-Williams, D., 2002, The mind in the cave: Consciousness and the origins of art, Thames and Hudson 2002, New York.

Lewis-Williams, D., 2010, Conceiving God: The cognitive origin and evolution of religion, Thames \& Hudson, London.

McClenon, J., 1997, 'Shamanic healing, human evolution, and the origin of religion', Journal for the Scientific Study of Religion 36(3), 345-354. https://doi. org/10.2307/1387852

McClenon, J., 2002, Wondrous healing: Shamanism, human evolution, and the origin of religion, Northern Illinois University Press, De Kalb, IL.

McNamara, P., 2009, The neuroscience of religious experience, CUP, Cambridge.

Murray, M.J., 2009, 'Scientific explanations of religion and the justification of religious belief', in J. Schloss and M.J. Murray (eds.), The believing primate: Scientific, philosophical, and theological reflections on the origin of religion, pp. 168-177, OUP, Oxford.

Murray, M.J. \& Goldberg, A., 2009, 'Evolutionary accounts of religion', in J. Schloss and M.J. Murray (eds.), The believing primate: Scientific, philosophical, and theological reflections on the origin of religion,pp. 178-199, OUP, Oxford.

Reynhout, K.A., 2015, 'Human evolution and the nature of morality', Theology Today 72(2), 135-140.

Schloss, J. \& Murray, M. (eds.), 2009, The believing primate: Scientific, philosophical, and theological reflections on the origin of religion, OUP, Oxford.

Sosis, R., 2009, 'The Adaptationist-Byproduct Debate on the evolution of religion: Five Misunderstandings of the Adaptationist Program', Journal of Cognition and Culture 9(3), 315-332.

Teehan, J., 2014, 'Cognitive science and the limits of theology' in R. Trigg and J. Barret (eds.), The roots of religion. Exploring the cognitive science of religion, pp. 167-188, Ashgate Publishing, Surrey, UK. 
Van Huyssteen, W.J., 2006, Alone in the world? Human uniqueness in science and theology, Wm. B. Eerdmans, Grand Rapids, MI.

Van Huyssteen, W.J., 2011, 'What makes us human? The interdisciplinary challenge to theological anthropology and Christology', Toronto Journal of Theology 26(2), 143-160.

Van Huyssteen, W. J., 2014, 'From empathy to embodied faith: Interdisciplinary perspectives on the evolution of religion', in F. Watt \& L. Turner (eds.), Evolution, religion, and cognitive science: Critical and constructive essays, pp. 132-151, Oxford University Press, Oxford.
Visala, A., 2011, Naturalism, theism, and the cognitive study of religion. Religion explained? Ashgate Publishing, Farnham, UK.

Wade, N., 2009, The faith instinct: How religion evolved and why it endures, The Penguin Press, New York.

Wildman, W.J., 2009, Science and religious anthropology, Ashgate Publishing, Farnham, UK.

Wuketits, F.M., 1990, Evolutionary epistemology and its implications for humankind, SUNY Press, Albany, NY. 